\title{
Correction to: Surface Plasmon Assisted Luminescence Enhancement of Ag NP/NWs-Doped SiO2-TiO2-ZrO2:Eu3+ Ternary System
}

\author{
V. P. Prakashan ${ }^{1}$ - M. S. Sajna ${ }^{1}$ - G. Gejo ${ }^{1}$ - M. S. Sanu ${ }^{1}$ - A. C. Saritha ${ }^{1}$ - P. R. Biju ${ }^{1} \cdot$ J. Cyriac $^{1}$ • N. V. Unnikrishnan ${ }^{1}$
}

Published online: 8 April 2020

(C) Springer Science+Business Media, LLC, part of Springer Nature 2020

Correction to: Plasmonics (2019) 14:673-683

https://doi.org/10.1007/s11468-018-0845-9

The original version of this article unfortunately contained a mistake. There is a technical error in Figure 1 of the manuscript and the corrected figure is given below.

The online version of the original article can be found at https://doi.org/ 10.1007/s11468-018-0845-9

\footnotetext{
N. V. Unnikrishnan nvu100@yahoo.com

1 School of Pure and Applied Physics, Mahatma Gandhi University, Kottayam 686 560, India
} 

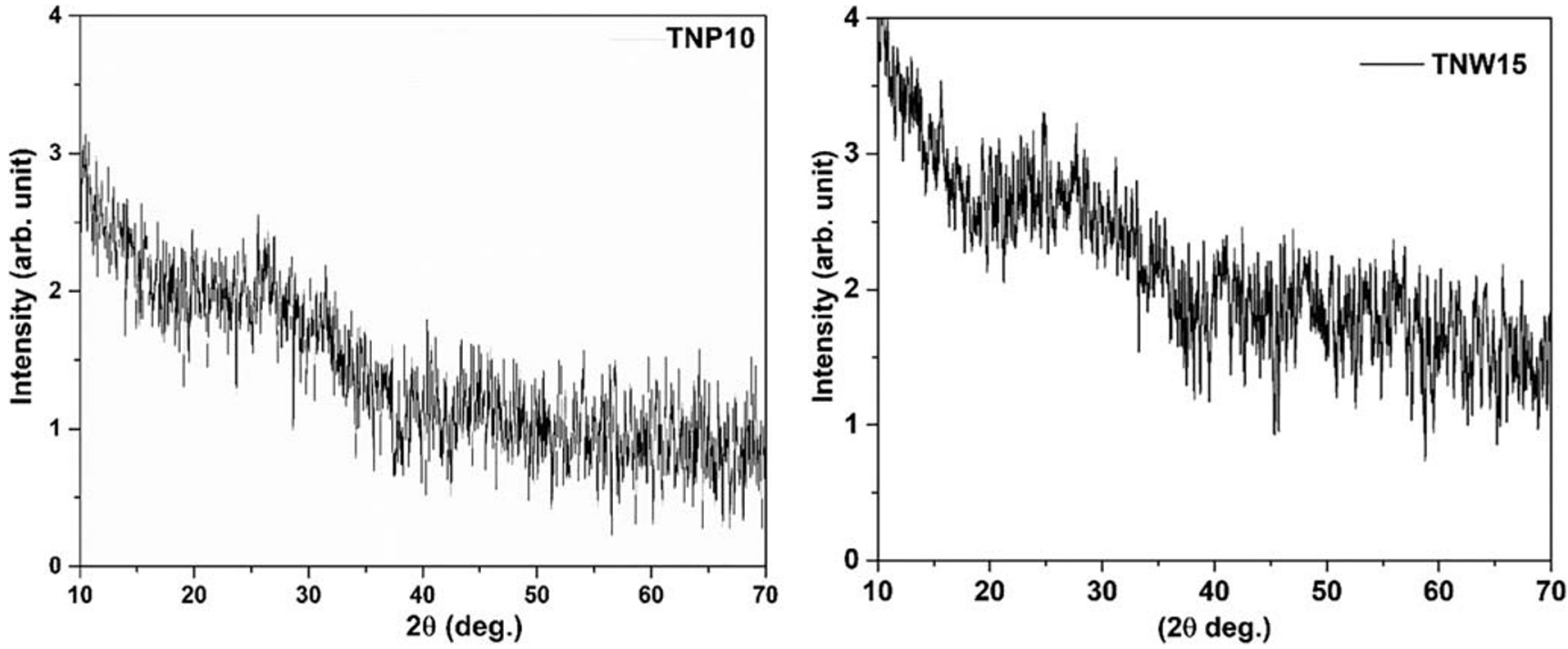

Fig. 1 XRD patterns of TNP10 and TNW15 recorded over the range 10-70

Publisher's note Springer Nature remains neutral with regard to jurisdictional claims in published maps and institutional affiliations. 